\title{
New onset hyperglycemia attributed to renal cell carcinoma
}

\author{
Jonathan Gapp ${ }^{1}$, Muhammad Fazeel Anwar ${ }^{1}$, Jai Parekh ${ }^{1, *}$, Timothy Griffin ${ }^{2}$ \\ ${ }^{1}$ Department of Internal Medicine, Creighton University Medical Center, Omaha, NE, USA; \\ ${ }^{2}$ Department of Internal Medicine, VA Omaha Medical Center, Omaha, NE, USA.
}

\begin{abstract}
Summary A 61-year-old male was admitted from the outpatient setting for treatment of severe hyperglycemia. Five months earlier, his hemoglobin A1c had been $5 \mathrm{mmol} / \mathrm{mol}$. At presentation, hemoglobin $A 1 \mathrm{c}$ was $11.3 \mathrm{mmol} / \mathrm{mol}$ and he required insulin therapy at discharge. Later magnetic resonance imaging (MRI) identified bilateral renal masses, previously seen on ultrasound during workup for chronic kidney disease, as being suspicious for renal cell carcinoma (RCC). He underwent partial nephrectomy and cryoablation with pathology showing papillary type RCC. Hyperglycemia resolved after resection and insulin therapy was discontinued, requiring only an oral hypoglycemic. Hyperglycemia as a paraneoplastic syndrome related to RCC is rare. The cause of this acute hyperglycemia is not understood, though previously suggested mechanisms include ectopic glucagon production, autoimmune causes and interleukin-6 (IL-6) mediated pathways. Severe, newonset hyperglycemia in the absence of common causes and with a renal mass on imaging may represent an uncommon paraneoplastic syndrome secondary to RCC.
\end{abstract}

Keywords: Hyperglycemia, malignancy, paraneoplastic syndrome, renal cell carcinoma

\section{Introduction}

Renal cell carcinoma ( $\mathrm{RCC}$ ) has an incidence of approximately 65,000 cases annually in the United States with approximately 15,000 deaths a year (1). Over time, mortality rates have been steadily decreasing along with decreasing tumor size at the time of initial finding, likely due to an increased rate of incidental detection on abdominal imaging (2). Currently, most RCC is diagnosed while the disease is still localized, with $65 \%$ of cases diagnosed while still confined to the kidney. While earlier stages of RCC have a 5-year survival of approximately $90 \%$, stages III and IV have a 5-year survival rate of 59-70\% and median survival of 1 year respectively. It is estimated that approximately $20 \%$ of patients with RCC will have manifestations of paraneoplastic syndromes and in a significant number of patients; this may be the presenting complaint leading

Released online in J-STAGE as advance publication May 25, 2018.

*Address correspondence to:

Dr. Jai Parekh, Department of Internal Medicine, Creighton University Medical Center, 7500 Mercy Rd, Omaha, NE 68124, USA.

E-mail: jaiparekh@creighton.edu to a diagnostic workup and detection of RCC (3). The most common paraneoplastic syndromes associated with RCC are anemia, erythrocytosis, thrombocytosis, fever, cachexia, AA amyloidosis, hepatic abnormalities (Staufer's syndrome), and polymyalgia rheumatica. Only a handful of cases have reported hyperglycemia secondary to RCC paraneoplastic syndrome with one case reported in the past decade. Here we describe the case of a patient whose presentation with severe hyperglycemia without previous history of diabetes, contributes to the diagnosis of renal cell carcinoma.

\section{Case Report}

A 61-year-old male with a history of essential hypertension, hyperlipidemia, coronary artery disease with past stenting and chronic kidney disease (CKD) was sent for admission from his nephrologist's office in October of 2016 when found to have serum blood glucose of $667 \mathrm{mg} / \mathrm{dL}$. Per hospital records, the patient had not had a hemoglobin Alc over $5.5 \mathrm{mmol} / \mathrm{mol}$ since the beginning of his records 8 years ago with no diabetes medication during that time. A month prior to admission, the patient was started on metformin 500 mg twice daily by another provider and he reported he had run out of medication 10 days ago. At presentation, 
he complained of fatigue, polyuria, polydipsia, blurred vision and lightheadedness. Further review revealed the patient had a renal ultrasound a month before this admission while establishing care with a nephrologist for management of his CKD. At that time, bilateral renal masses included a $3.8 \times 2.9 \times 3.7 \mathrm{~cm}$ hypo echoic, exophytic mass on the right kidney and 1.6 $\mathrm{cm} 1.3 \times 1.4 \mathrm{~cm}$ hypo echoic solid mass on the left kidney. Suggestion for urologic consultation and further imaging to rule out malignancy had been made, though these had not yet been completed.

On physical exam, the patient was afebrile with heart rate of 89 beats per minute and blood pressure of $104 / 74 \mathrm{mmHg}$ and saturating at $96 \%$ on room air. He was not in distress, oral mucosa was dry and he was alert, awake and oriented. Lab values were significant for sodium of $129 \mathrm{mEq} / \mathrm{L}$, potassium $4.8 \mathrm{mEq} / \mathrm{L}$, bicarbonate of $22 \mathrm{mEq} / \mathrm{L}$, blood urea nitrogen of 36 $\mathrm{mEq} / \mathrm{L}$, serum creatinine of $2.3 \mathrm{mEq} / \mathrm{L}$ and serum glucose of $667 \mathrm{mg} / \mathrm{dL}$. Calculated serum osmolality was $308 \mathrm{mOsm} / \mathrm{kg}$, liver panel was normal, white blood cell count of $6.3 \times 10^{3}$ cells $/ \mu \mathrm{L}$ and hemoglobin of 11.3 $\times 10^{6}$ cells $/ \mu \mathrm{L}$. Serum $\mathrm{pH}$ was 7.39 with no detectible beta-hydroxybutyrate and hemoglobin A1C was 11.3 $\mathrm{mmol} / \mathrm{mol}$ and otherwise ranging from 4.5-5.5 mmol/ mol over the last eight years.

During admission, computed tomography (CT) abdomen displayed a right indeterminate $3.6 \times 3.7 \mathrm{~cm}$ exophytic inferior cortical renal mass. Additionally, there was a $1.0 \times 0.7 \mathrm{~cm}$ left mid-pole lesion. Upon urologic evaluation, the $\mathrm{CT}$ scan findings were thought to be low risk for malignancy and reimaging in 6 months was suggested. The patient was discharged on insulin, requiring up to 43 units per day, with instruction to follow up with an ultrasound of the abdomen. Repeat ultrasound six months later revealed an enlarging right renal mass measured as $4.2 \times 4.0 \mathrm{~cm}$ in diameter and left to $1.3 \mathrm{~cm}$ and patient was scheduled for MRI to further characterize the mass. MRI re-demonstrated the right sided mass that had increased to $4.5 \mathrm{~cm}$ with diffuse post contrast enhancement (Figure 1) as well as left sided hypo-intense mass measuring $1.2 \mathrm{~cm}$ with post contrast enhancement (Figure 2) concerning for renal cell carcinoma. The patient underwent rightsided partial nephrectomy with pathology revealing papillary renal cell carcinoma, type 1 , and grade 2 . Immunohistochemical stains showed tumor cells positive for CK7 and vimentin and negative for CD117, consistent with a diagnosis of RCC (Figure 3). Left sided renal mass was treated with cryoablation and interventional radiologic (IR) embolization. The patient recovered well from his surgery and was discharged.

Four months after discharge, patient's hemoglobin Alc had trended down to $4.5 \mathrm{mmol} / \mathrm{mol}$ and he was switched from insulin to glipizide $2.5 \mathrm{mg}$. The patient was contacted after discharge and informed consent was obtained for publication of this study.

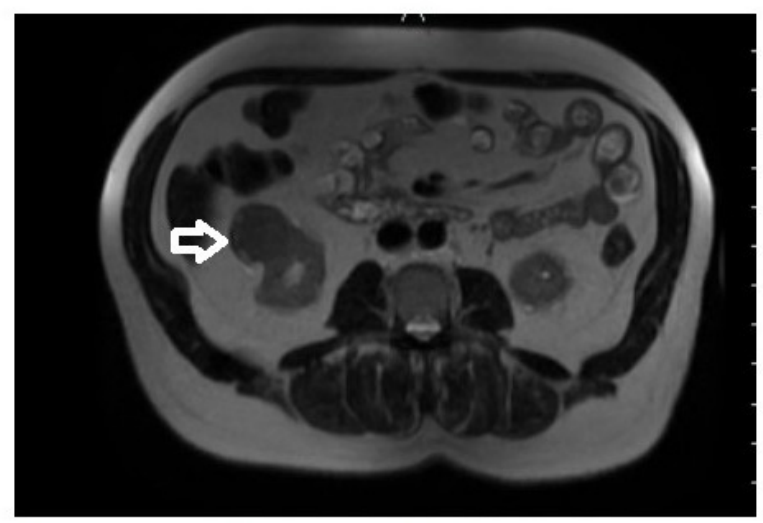

Figure 1. MRI of the abdomen displaying round exophytic mass of the right kidney increased to $4.5 \mathrm{~cm}$ from $4 \mathrm{~cm}$ a month prior.

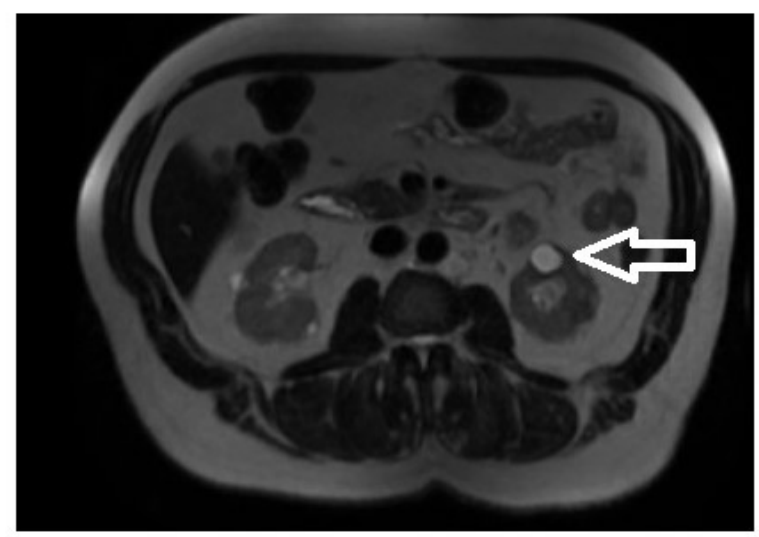

Figure 2. MRI of the abdomen displaying left sided, renal, hypo-intense mass measuring $1.2 \mathrm{~cm}$ with post contrast enhancement.

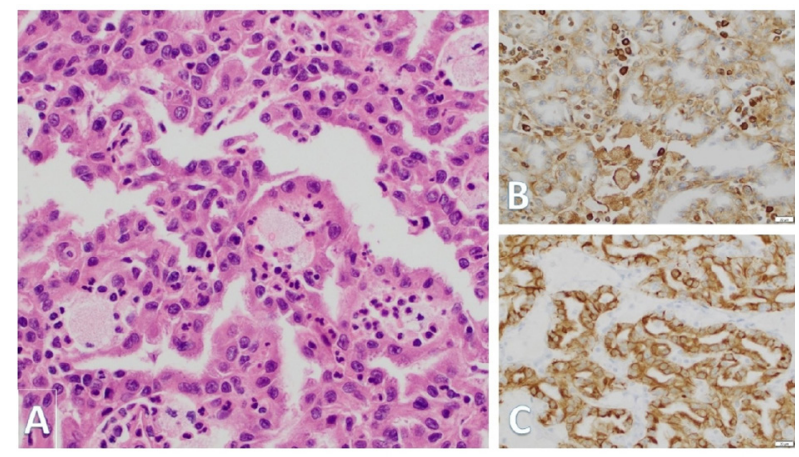

Figure 3. Histopathology of right renal mass following nephrectomy. (A) Hematoxylin and eosin stain; (B) Immunohistochemical staining positive for $\mathrm{CK} 7$ and for (C) Vimentin. The findings are consistent with a diagnosis of renal cell carcinoma.

\section{Discussion}

In this case, a patient with no former history of diabetes and with a hemoglobin A1c of $5.5 \mathrm{mmol} / \mathrm{mol}$ just five months prior to this hospitalization presented with severe hyperglycemia. During this five-month 
Table 1. Review of previously reported cases

\begin{tabular}{|c|c|c|}
\hline Author & Year & Synopsis \\
\hline Pavelic (6) & 1981 & $\begin{array}{l}59 \text { yo } \mathrm{F} \text {, no history given with left flank pain. Left kidney mass } 25 \times 15 \times 8 \mathrm{~cm} \text {. Detected high levels of serum } \\
\text { glucagon and insulin, which trend down after surgery, fluctuating blood sugars. }\end{array}$ \\
\hline Palgon (8) & 1986 & $\begin{array}{l}67 \text { yo F with no previous IDDM, presents with AMS and serum glucose } 650 \mathrm{mg} / \mathrm{dL} \text { and requires } 50 \mathrm{U} \text { insulin } \\
\text { per day. Eight cm diameter mass, no metastasis, clear cell type, glucagon and somatostatin stains negative. Right } \\
\text { radical nephrectomy with no insulin required after resection. }\end{array}$ \\
\hline Jobe $(10)$ & 1993 & $\begin{array}{l}66 \text { yo } \mathrm{M} \text {, with no previous IDDM, presents in DKA with serum glucose of } 847 \mathrm{mg} / \mathrm{dL} \text { and requires up to } 80 \mathrm{U} / \\
\text { day of insulin. Right renal mass } 9 \times 10 \times 11.5 \mathrm{~cm} \text {, no metastasis, and clear cell type. Right nephrectomy with no } \\
\text { insulin required after removal. Discharged on } 2.5 \mathrm{mg} \text { of glyburide. }\end{array}$ \\
\hline Callewaert (4) & 1999 & $\begin{array}{l}35 \text { yo } \mathrm{F} \text { with previous IDDM requires } 600 \mathrm{U} / \text { day of insulin at presentation. Bilateral multifocal papillary renal cell } \\
\text { carcinoma, grade 2, with no metastasis. Bilateral radical nephrectomy and returns to premorbid insulin use of } 80 \\
\text { U/day. }\end{array}$ \\
\hline Macaulay (7) & 2002 & $\begin{array}{l}69 \text { yo } \mathrm{M} \text { with previous non-IDDM (on gliclazide) with hyperglycemia and elevated alkaline phosphatase requiring } \\
\text { insulin (amount not specified). Six cm, right, necrotic mass, grade } 2 \text { with renal vein involvement, no metastasis. } \\
\text { Left radical nephrectomy with return to gliclazide after nephrectomy. }\end{array}$ \\
\hline Elias (5) & 2005 & $\begin{array}{l}52 \text { yo F with no previous IDDM admitted with DKA. Elevated anti-GAD and islet cell antibody, which normalized } \\
\text { after nephrectomy. Negative stain for glucagon, growth hormone and insulin. Insulin amounts prior and following } \\
\text { tumor removal not specified though noted as decreasing. }\end{array}$ \\
\hline Harada (9) & 2016 & $\begin{array}{l}68 \text { yo } \mathrm{F} \text { with no previous IDDM, presents with serum glucose } 353 \mathrm{mg} / \mathrm{dL} \text { and A1c of } 11.7 \mathrm{mmol} / \mathrm{mol} \text {, elevated } \\
\text { alkaline phosphatase requires } 43 \mathrm{U} / \text { day insulin. Type of RCC not specified, grade II. Right nephrectomy and } \\
\text { required } 750 \mathrm{mg} \text { metformin daily at } 2 \text { month follow up. }\end{array}$ \\
\hline
\end{tabular}

IDDM - insulin dependent diabetes, AMS - altered mental status, DKA - diabetic ketoacidosis, GAD - glutamic acid decarboxylase, RCC renal cell carcinoma.

period, the patient was found to have new, bilateral renal masses. The acute elevation of hemoglobin A1c to $11.3 \mathrm{mmol} / \mathrm{mol}$ is an atypical presentation of new onset diabetes in the absence of steroid use, severe pancreatitis, pancreatic cancer or pancreatectomy. Insulin therapy was required for 6 months with up to 43 units of long acting insulin per day at peak usage. Insulin requirements did appear to fluctuate rather dramatically, eventually requiring only glipizide. Following nephrectomy, the patient was able to remain on low dose oral hypoglycemic therapy as his hemoglobin A1c fell to $4.5 \mathrm{mmol} / \mathrm{mol}$. This presentation and resolution of hyperglycemia following right-sided partial nephrectomy with embolization and cryoablation of the left sided mass is strongly suggestive of RCC as cause of the hyperglycemia.

A review of the literature revealed 7 previously reported cases of RCC with hyperglycemia in the English literature that were available for review (410). Years of publication ranged from 1981 to 2016 . Available patient demographics and case details are included below (Table 1). One of the seven patients presented in diabetic ketoacidosis (DKA) (5). In all cases, there was improvement in glycemic control following nephrectomy. Both clear cell type and papillary type of RCC have been documented as causing these hyperglycemic states, however most case reports have not noted the histologic type of RCC. Furthermore, there are not enough cases reported to determine strength of correlation between RCC type and this hyperglycemic syndrome.

While the mechanism of hyperglycemia as a paraneoplastic syndrome in RCC has not yet been elucidated, a few possible mechanisms have been presented. One case noted increased levels of glucagon, which trended down after nephrectomy and presents the possibility of an endocrine mechanism of hyperglycemia (6). Another case detected elevation of anti-glutamic acid dehydroxylase (GAD) and antiislet cell antibodies, which also normalized following nephrectomy and suggested a possible insulin deprivation mechanism due to pancreatic dysfunction on the level of the beta-islet cell (5). However, a review of the few other cases is not consistent with these previously noted findings. For instance, in the case of Harada et al, anti-GAD was tested for but was negative (9). For Calleawart and colleagues, glucagon, growth hormone, insulin like growth factor, cortisol and adrenocorticotropic hormone levels were all reported as normal (4). It may be that multiple mechanisms account for these few cases of significant hyperglycemia. More recent theories point to the effects of IL-6, which plays a role in other RCC paraneoplastic syndromes as well. In a study comparing cancer vs non-cancer patients, there was significantly decreased uptake of glucose in cancer patients with elevated IL-6 levels compared to those without elevated IL-6 (11). In other studies, injection of recombinant human IL-6 increased plasma glucose levels in a dose-dependent manner (12) and decreased insulin secretion from beta-islet cells (13). 
Also, Blay and his colleagues studied the role of IL-6 levels in multiple paraneoplastic syndromes in patients with metastatic RCC and found that $90 \%$ of these patients had elevated IL-6 levels (14). Previous works by his group also showed expression of IL-6 from RCC cells in vitro as well. However, if $90 \%$ of patients with RCC have elevated levels of IL-6, the question of why so few cases of severe, new-onset hyperglycemia exist in RCC patients remains.

Hyperglycemia as a paraneoplastic syndrome in $\mathrm{RCC}$ is rare. The few reported incidences often show acute and severe hyperglycemia, which resolves with nephrectomy, as seen in the present case. These cases collectively indicate RCC as the most plausible cause of hyperglycemia. Further study is needed to determine the mechanism of hyperglycemia in RCC. While it is obvious that every episode of new onset hyperglycemia does not warrant a workup for RCC, new onset of severe hyperglycemia with common causes excluded and the presence of other signs of RCC might indicate a paraneoplastic etiology.

\section{References}

1. Siegel RL, Miller KD, Jemal A. Cancer statistics, 2018. CA Cancer J Clin. 2018; 68:7-30.

2. Kane CJ, Mallin K, Ritchey J, Cooperberg MR, Carroll PR. Renal cell cancer stage migration: Analysis of the National Cancer Data Base.. Cancer. 2008; 113:78-83.

3. Palapattu GS, Kristo B, Rajfer J. Paraneoplastic syndromes in urologic malignancy: The many faces of renal cell carcinoma. Rev Urol. 2002; 4:163-170.

4. Callewaert PR, Van Poppel H, Vanderschueren D, Baert L. Uncontrollable diabetes mellitus: A rare paraneoplastic manifestation of renal cell carcinoma. Nephrol Dial
Transplant. 1999; 14:2263-2264.

5. Elias AN. New-onset insulinopenic diabetes mellitus in a patient with an incidentally discovered renal cell carcinoma. Am J Med. 2005; 118:1047-1048.

6. Pavelić K, Popović M. Insulin and glucagon secretion by renal adenocarcinoma. Cancer. 1981; 48:98-100.

7. Macaulay CP, Pati JJ, Carr TW, Bishop A. Renal cell carcinoma presenting with hyperglycaemia. BJU Int. 2002; 89:789-790.

8. Palgon N, Greenstein F, Novetsky AD, Lichter SM, Rosen Y. Hyperglycemia associated with renal cell carcinoma. Urology. 1986; 28:516-517.

9. Harada Y, Hara Y. Incidentally diagnosed renal cancer following investigation for new-onset hyperglycemia. Case Reports in Internal Medicine. 2016; 3:22.

10. Jobe BA, Bierman MH, Mezzacappa FJ. Hyperglycemia as a paraneoplastic endocrinopathy in renal cell carcinoma: A case report and review of the literature. Nebr Med J. 1993; 78:349-351.

11. Makino T, Noguchi Y, Yoshikawa T, Doi C, Nomura K. Circulating interleukin 6 concentrations and insulin resistance in patients with cancer. Br J Surg. 1998; 85:1658-1662.

12. Tsigos C, Papanicolaou DA, Kyrou I, Defensor R, Mitsiadis CS, Chrousos GP. Dose-dependent effects of recombinant human interleukin-6 on glucose regulation. J Clin Endocrinol Metab. 1997; 82:4167-4170.

13. Southern C, Schulster D, Green IC. Inhibition of insulin secretion from rat islets of langerhans by interleukin-6. An effect distinct from that of interleukin-1. Biochem J. 1990; 272:243-245.

14. Blay JY, Rossi JF, Wijdenes J, Menetrier-Caux C, Schemann S, Négrier S, Philip T, Favrot M. Role of interleukin- 6 in the paraneoplastic inflammatory syndrome associated with renal-cell carcinoma. Int $\mathrm{J}$ Cancer. 1997; 72:424-430.

(Received April 12, 2018; Revised May 12, 2018; Accepted May 19, 2018) 